\title{
Seismic Hazard Model Harmonization in Tienshan Area
}

\author{
Changlong $\mathrm{Li}^{*}$, Mengtan Gao \\ Institute of Geophysics, China Earthquake Administration, Beijing 100081, China
}

Received November 23, 2018

Accepted April 12, 2019

\begin{abstract}
This paper provides a comparison between Central Asia, the Middle East hazard models and the Chinese hazard result in Tienshan Area, based on reshaped seismogenic sources, recalculated related seismicity parameters, and calibrated ground motion models. This paper concluded that in the most areas of Tienshan, the Peak Ground Acceleration (PGA) with $10 \%$ probability of exceedance in 50 years is around $0.2 \mathrm{~g} \sim 0.3 \mathrm{~g}$, and northern part of Pakistan has the highest seismic hazard in Tienshan Area.
\end{abstract}

Keywords: Tienshan, Seismic hazard, Model harmonization, Peak Ground Acceleration

\section{Introduction}

Strong earthquake ground motion can cause destruction of the buildings, and lead to earthquake disasters. It is of great help to prevent earthquake disasters by providing appropriate seismic input parameters for structural design, risk assessment for mitigation actions. Therefore, seismic hazard and risk assessment has important practical and social value.

Probabilistic Seismic Hazard Assessment (PSHA) has become the standard procedure to evaluate the earthquake destructive potential within earthquake prone regions. Regional seismic hazard assessment provides means of harmonization of data, information and knowledge without country borders (Giardini et al., 2014). Often, the national hazard models are built based on data and information within the country border, neglecting contribution of earthquakes occurring in the neighboring countries. Therefore, along those country borders, there may be several hazards because different institutions may use different datasets and methods to build different hazard models. If we want to get a fully harmonized seismic hazard models and results for the entire region, the seismic hazard model harmonization at the borders in mandatory. This is what we managed to do in this paper.

We consider a study area sound the Tienshan region, Western China (Fig. 1). Tienshan region is located in the center of the Eurasian Continent, which can be separated into South Tienshan and North Tienshan. Three seismic hazard models are available at the border of this region, including model for Central Asia (EMCA, Bindi et al), the Middle East (Danciu et al 2015) and China (General Administration of Quality Supervision et al, 2015) respectively. Tienshan region is located right at the intersection of these regions, and these regional projects provide different hazard results given different level of completeness of earthquake catalogues, seismogenic and ground motion models in the same area. Consequently, it is meaningful to make a harmonized PSHA in Tienshan Area.

Bindi et al. (2012) conducted a PSHA study in Central Asia. In this study, the seismogenic sources are delineated as area sources due to

\footnotetext{
*Sponsored by: International partnership program of Chinese Academy of Sciences (131551KYSB 20160002); Fundamental Scientific Research Fund (DQJB17T04).

Correspondence to: Changlong Li, Institute of Geophysics, China Earthquake Administration, No. 5 Minzu Daxue Nanlu Road, Beijing 100081, China. Tel: +86 10 68729162; Fax: +86 10 68729162; E-mail: changlongli@163.com
} 


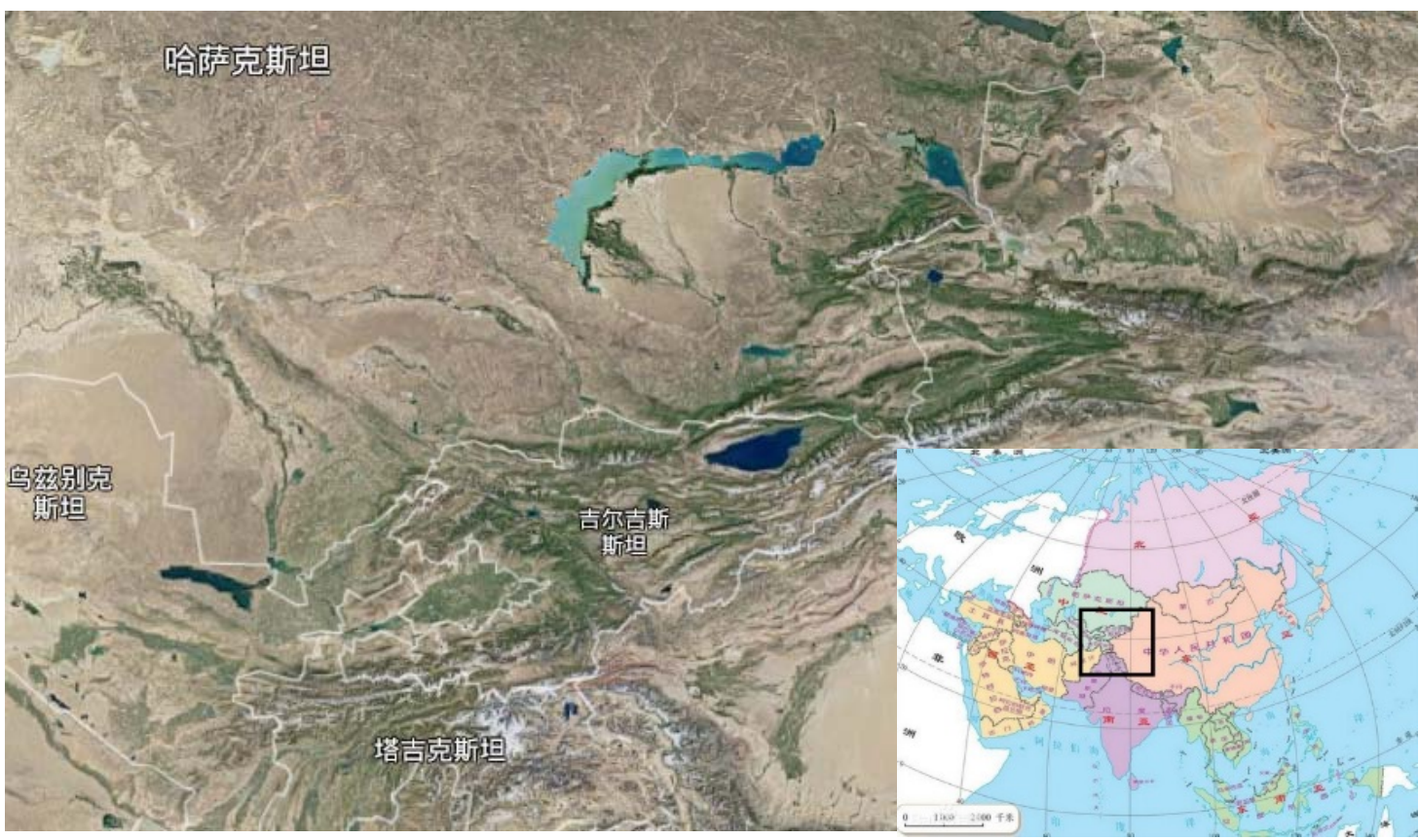

Fig. 1. Study area - Tienshan.

lack of key information on active faults (i.e. geological slip-rates). However, epistemic uncertainty on the spatial distribution of the seismicity is quantified by an alternative approach of smoothing the earthquake catalogue with different kernels (for further information of the EMCA seismogenic model sees Ullah et al 2015). The seismicity model only considers shallow earthquakes with focal depth less than $50 \mathrm{~km}$. The ground shaking is described by a regionally calibrated intensity prediction equation, describing the MSK64 macroseismic intensity scale (Bindi et al., 2011). The regional hazard model is implemented in OpenQuake (Pagani et al., 2015) and used to evaluate the spatial distribution of intensity with different probabilities of exceedance for Central Asia (Fig. 2).

The hazard estimates given in Fig.2 indicates the $10 \%$ probability of exceedance in 50 years for MSK64 intensity in the region; as it can be seen the MSK64 intensity of VIII is observed in the vicinity of the southern Tienshan. Details of the seismogenic source models, earthquake catalogue and details of the model development are given in Ullah et al 2015. The relevant seismogenic source model and the input to OpenQuake are available online: http://pmd.gfz-potsdam.de/panmetaworks/show short.php?id=escidoc: 1199628

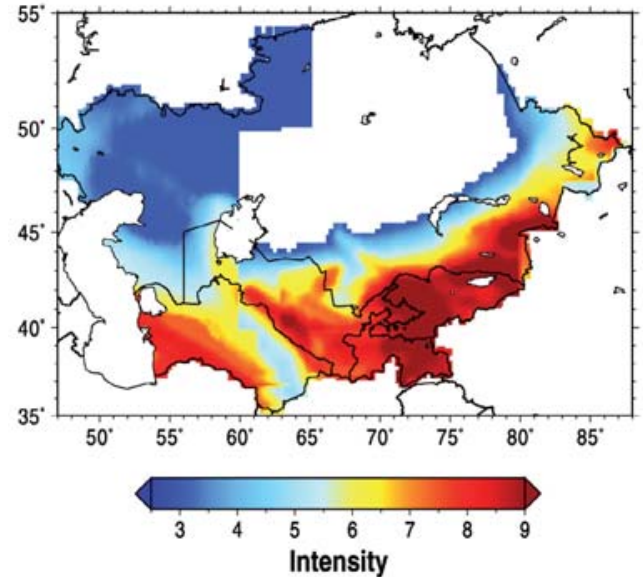

Fig. 2. Intensity map with $10 \%$ probability of exceedance in 50 years of Central Asia (Bindi et al, 2015)

Within the Earthquake Model of the Middle East, a fully harmonized hazard model was developed to cover the Middle East region. In 2015, Danciu et al. made PSHA for the Middle East. They weighted averaged the hazard result by area source model and fault source model, and got a hazard map of Peak Ground Acceleration (PGA) with $10 \%$ probability of exceedance in 50 years of the area (Fig. 3).

In 2016, the fifth version of Seismic Hazard Map of China (Fig. 4, GB 18306-2015.) was published. This map uses area source model for the whole China and shows seismic hazard of PGA with $10 \%$ probability of exceedance in 50 years of China. 


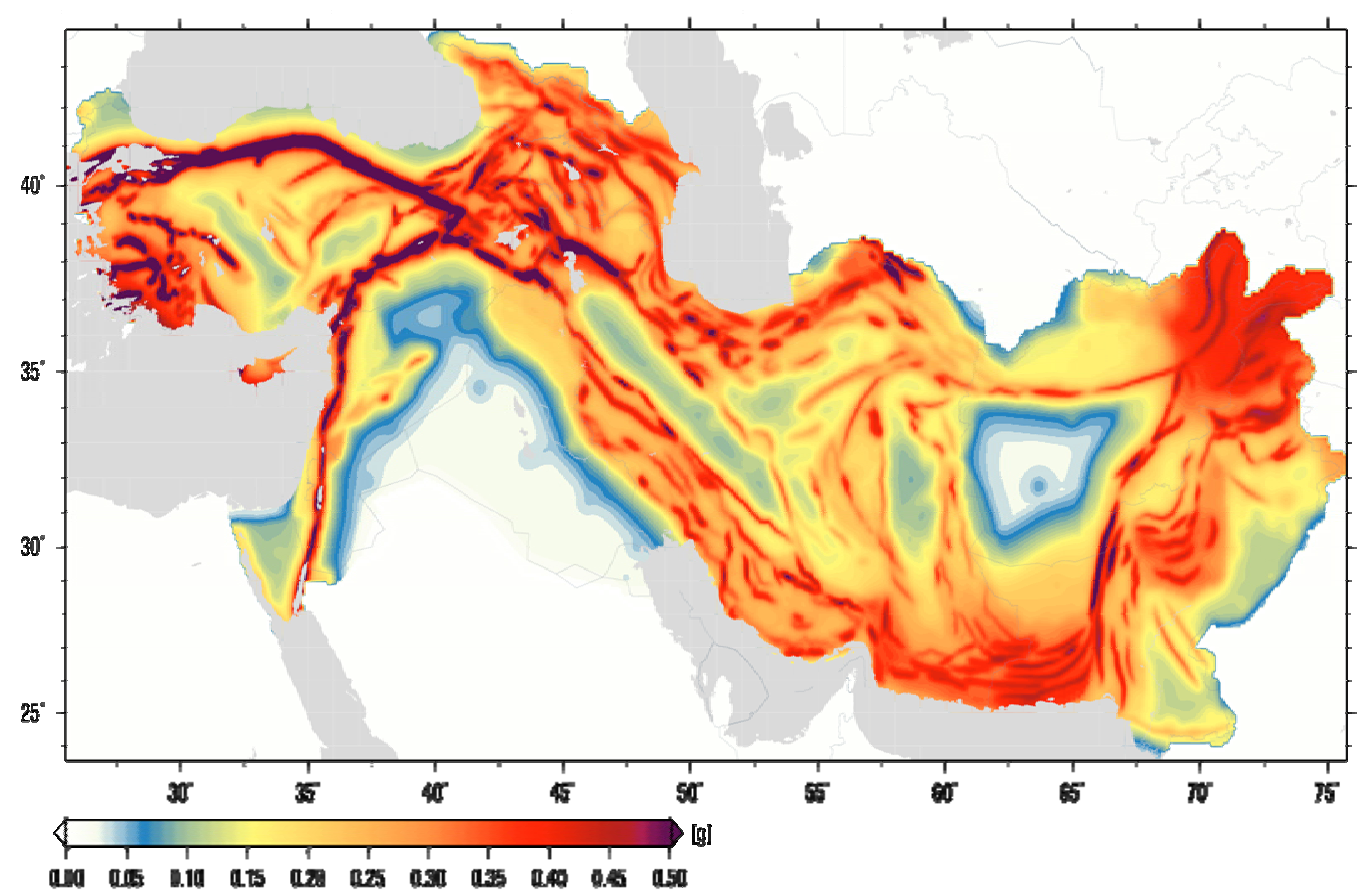

Fig. 3. Seismic hazard map of PGA with $10 \%$ probability of exceedance in 50 years of the Middle East

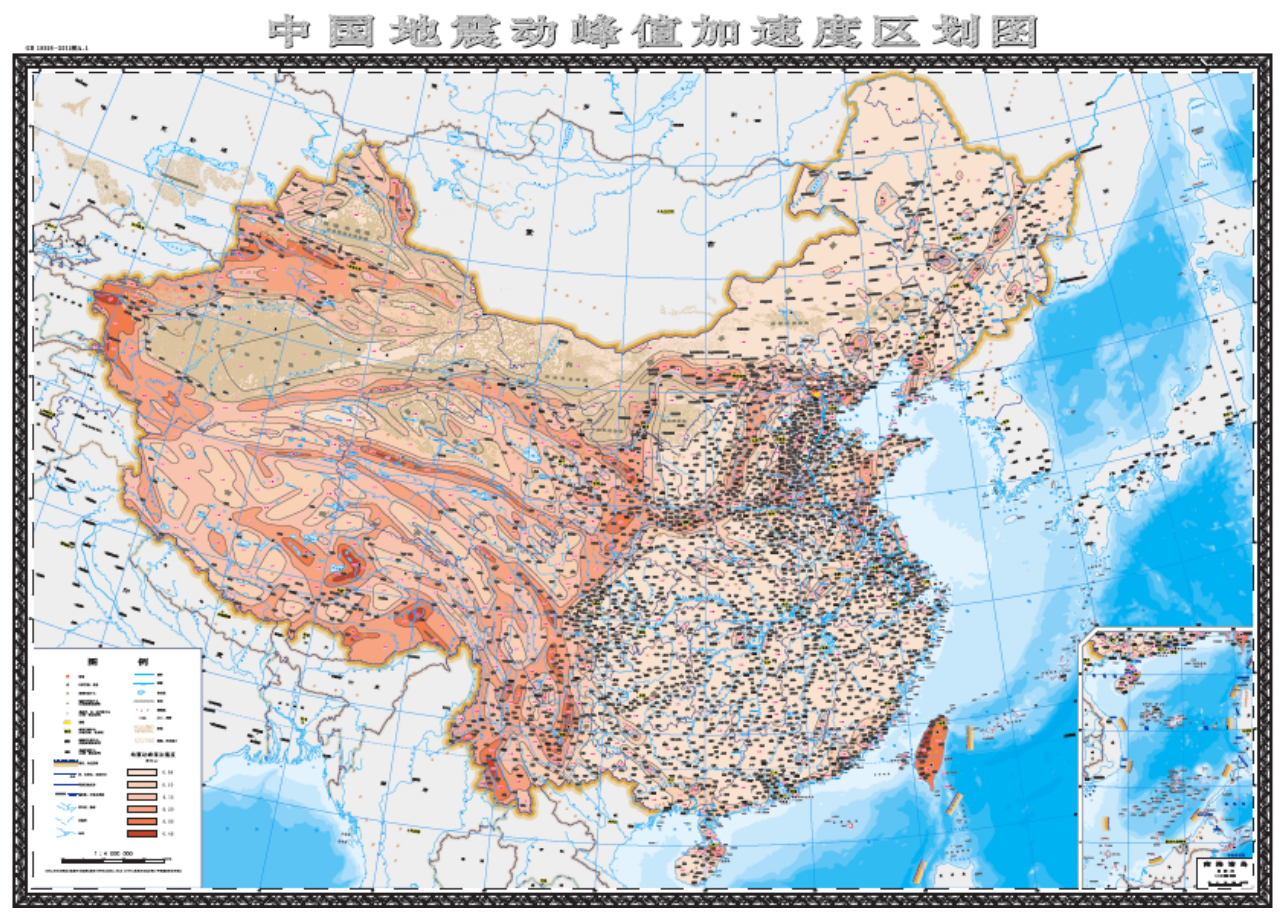

Fig. 4. The fifth version of Seismic Hazard Map of China (GB 18306-2015)

The seismic hazards around Tienshan Area are partly included in each of the studies above. But there are some problems to solve. The studies uses different ground motion parameters (intensity and PGA); and some studies use fault model but some studies not. In this paper, we managed to build a harmonized seismic hazard model for Tienshan Area and give a harmonized seismic hazard result.

\section{Seismic Hazard Model Harmonization of South Tienshan}

\subsection{Seismogenic source model}

\section{Central Asia}

Seismogenic source model in Central Asia is built by the project of Earthquake Model of Central Asia (EMCA, Bindi et al. 2012), as shown in Fig. 5. Central Asia is separated into 


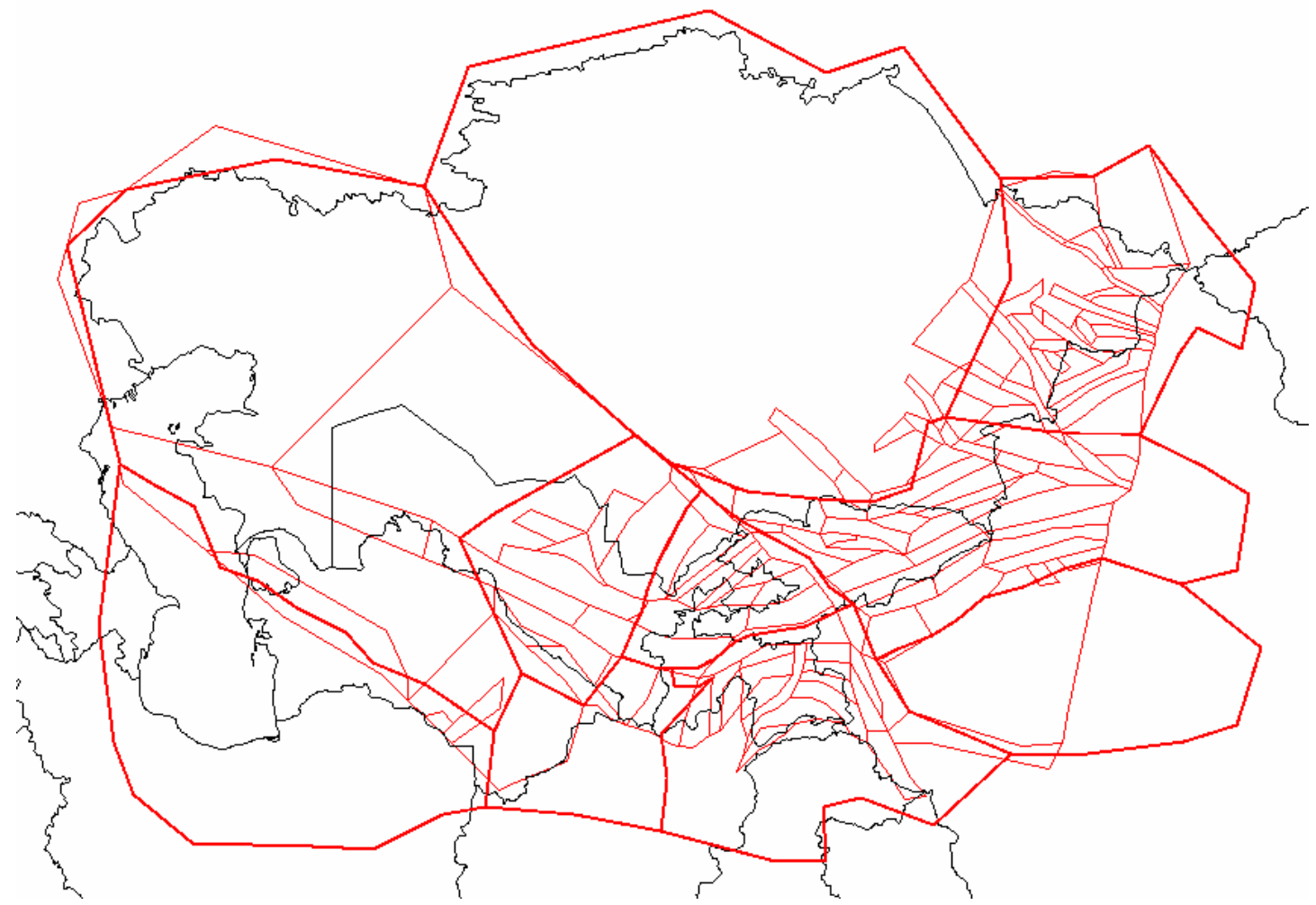

Fig. 5. Seismogenic sources of EMCA (Bindi et al. 2012)

ten seismic belts (in thick red lines) and 131 seismogenic sources (in thin red lines) in total. EMCA is separated into two tectonic regions: Active Shallow Crust and Stable Continental Crust. In every seismogenic source, the seismicity is in accordance with a truncated exponential distribution. And the b-values of the seismogenic sources in the same seismic belt are the same.

\section{The Middle East}

Seismogenic source model in the Middle East is built by the project of Earthquake Model of the Middle East (EMME, Danciu et al, 2015), as shown in Fig. 6. The Middle East Area is

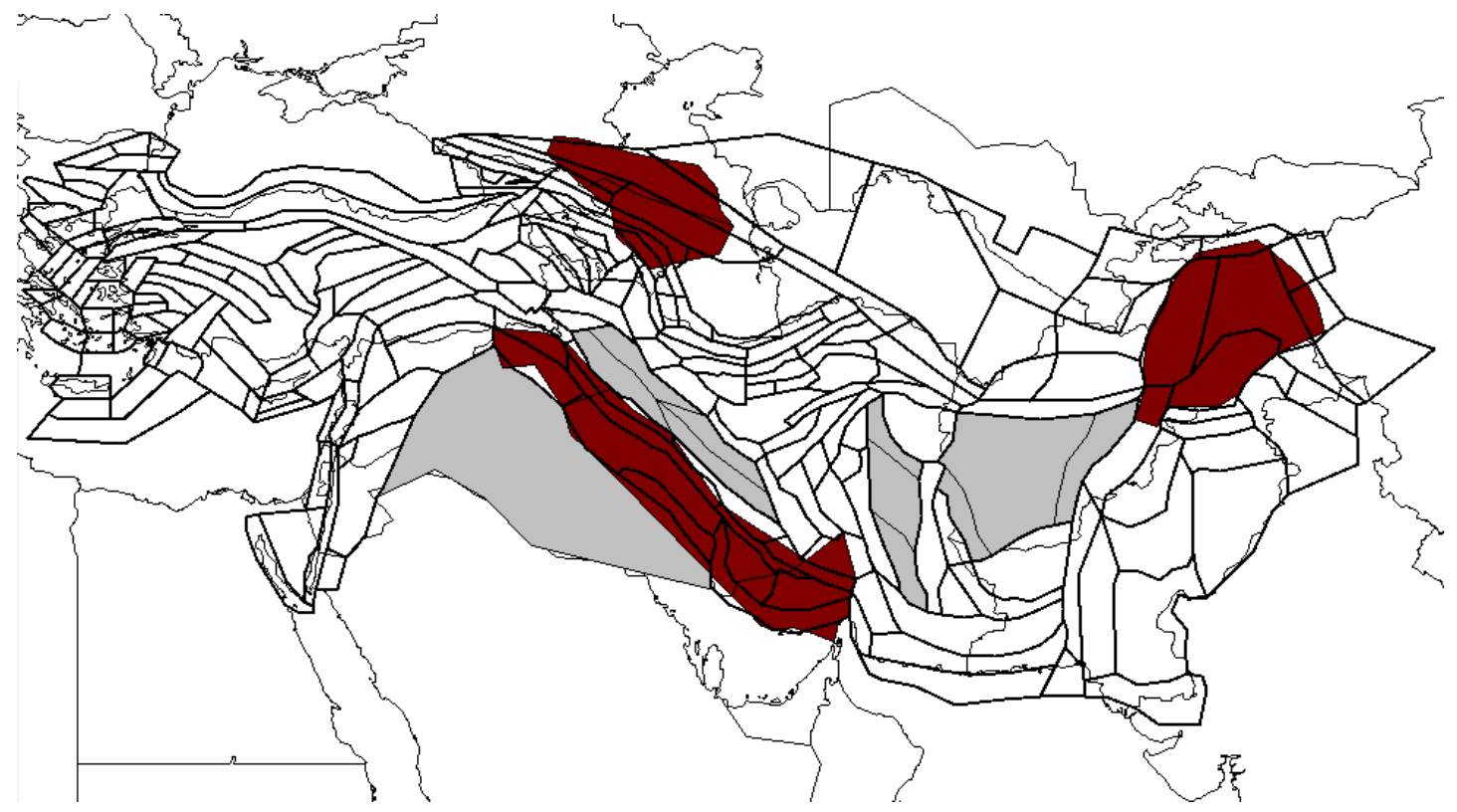

Fig. 6. Seismogenic sources of EMME (Danciu et al, 2015). 
separated into three tectonic types: Active Shallow Crust (ASC, in white), Stable Continental Crust (SCC, in gray) and Subduction Intraslab (SI, in brown). In the Middle East, there are 213 ASCs, eleven SCCs and six SIs in total.

\section{China}

Zhou et al (2013) analyzed earthquake activity characteristics in China and surrounding areas, and pointed out the principle of three-level delineation of seismogenic sources. This zonation model relies on two main assumptions:

(1) Zoning seismic belts (the broadest areas included in the model) are areas where the magnitude-frequency relation follows a classical G-R relation (Gutenberg and Richter, 1944). The seismic belts contain seismotectonic provinces (sources of background seismicity, SBG) with different seismicity characteristics; finally, SBGs include seismic sources (sources of seismic tectonism, SST) mainly located around active tectonic faults. The three-level delineation of seismogenic sources is a main feature of seismogenic sources zoning in China. The 2015 version of the China national hazard model contains 29 seismic belts (Fig. 7), 444 SBGs and 1199 SSTs (Fig. 8) zoned nationwide.

(2) The difference of tectonic activity environment between east and west China is considered. The methods and basis of zoning of SBGs and SSTs in the east and west focus on different points. In western areas, we focus on boundaries of different levels of active blocks controlling major earthquake activity (Zhang et al, 2003). Different types of seismogenic sources models are created and tectonic analogy principles are fully used under seismogenic sources framework to zone new potential sources and avoid underestimating earthquake capacity in high-magnitude SSTs. In eastern areas, we focus on the recognition of strong earthquake tectonic belts, and enrich the basis of zoning strong earthquake SSTs.

It is also noted that, in this seismogenic sources model, seismogenic sources are the surface projection of macro-epicenter of potential earthquakes.

\subsection{Hazard result comparison between} EMCA-EMME and China

To get harmonized seismic hazard, we should know how different the results of the three models are. In fact, EMCA and EMME models have been harmonized when they were built, so we only need to compare the results of China and EMCA-EMME. Fig. 9 and Fig. 10 show seismic hazard calculated by China model and EMCA-EMME model respectively. Fig. 11 shows the difference of the two results (China

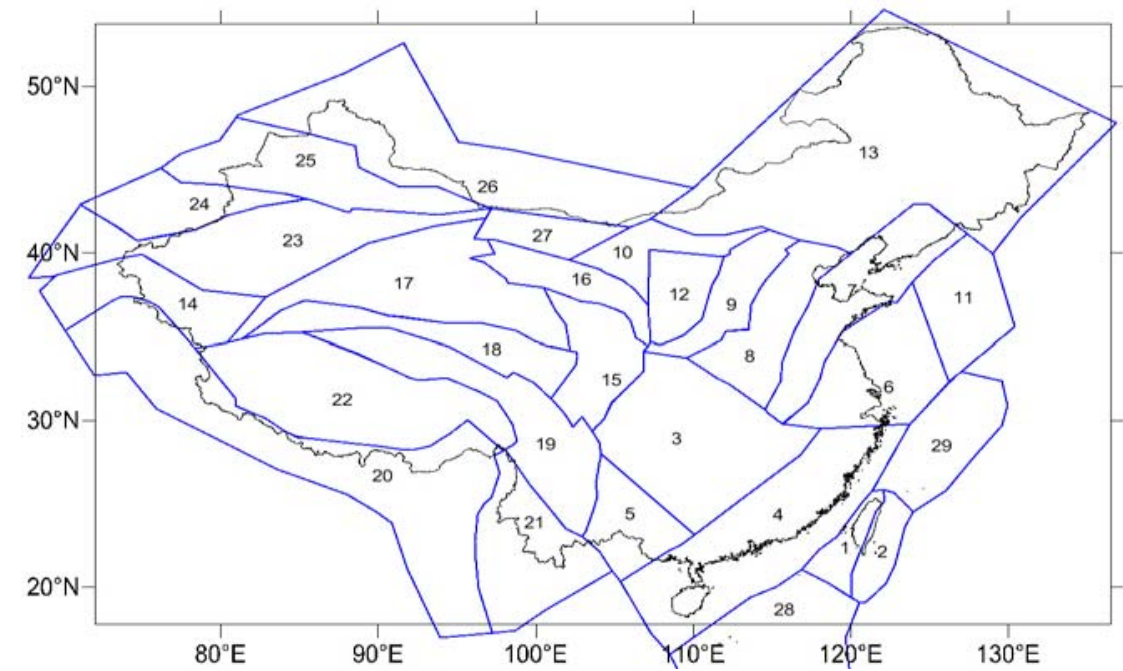

Fig. 7. Seismic belts in China (Gao et al, 2014). Names of seismic belts: 1. Western Taiwan; 2. Eastern Taiwan; 3. Midstream of Yangtze River; 4. South China; 5. Youjiang River; 6. Downstream of Yangtze River and Southern Huanghai Sea; 7. TanLu; 8. North China; 9. Fenwei; 10. Yinchuan-Hetao; 11. Korean; 12. Ordos; 13. Northeast China; 14. West Kunlun Mountain - Pamir; 15. Longmen Mountain, 16. Liupan - Qilian Mountain; 17. Qaidam Altun; 18. Bayan Har; 19. Xianshuihe - Eastern Yunnan; 20. Himalaya; 21. Southwestern Yunnan; 22. Central Tibet; 23. Southern Tianshan Mountain; 24. Middle Tianshan Mountain; 25. Northern Tianshan Mountain; 26. Altai Mountain; 27. Tarim - Alxa; 28. South China Sea; 29. East China Sea 


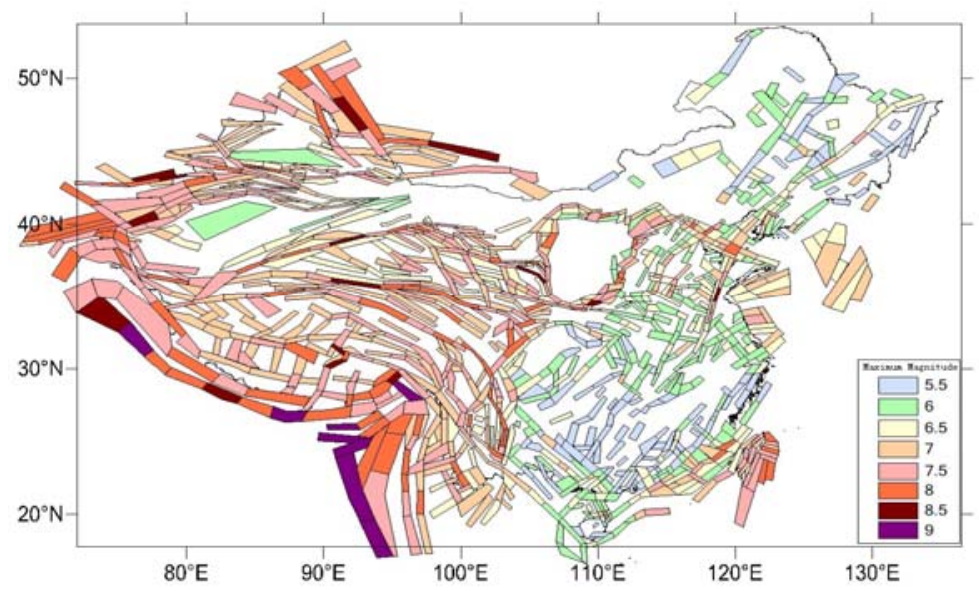

Fig. 8. Seismotectonic sources in China (Gao et al, 2014)

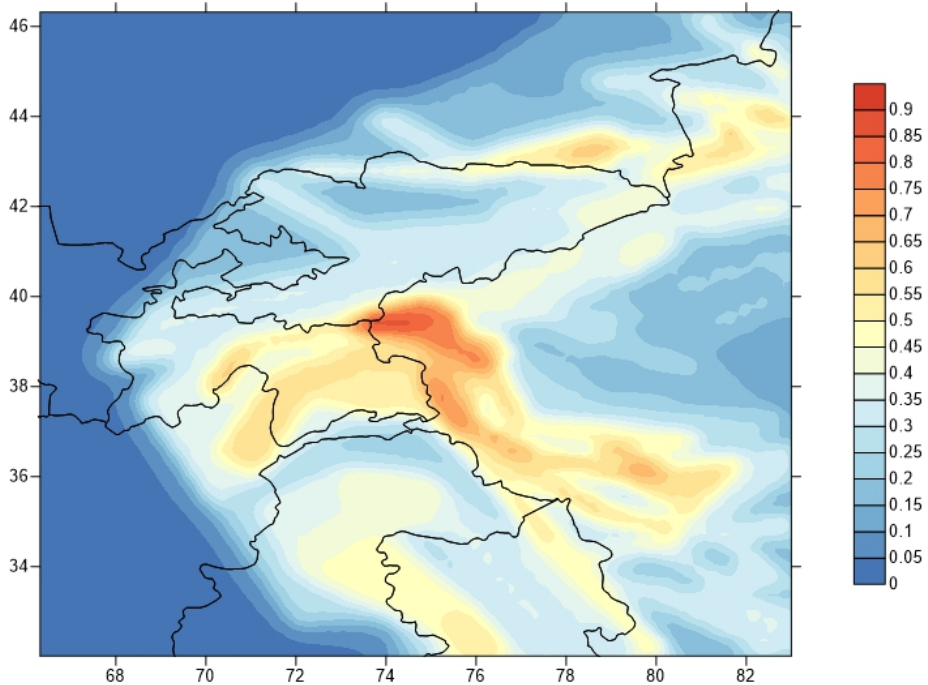

Fig. 9. Seismic hazard result calculated by China model (PGA with $10 \%$ probability of exceedance in 50 years)
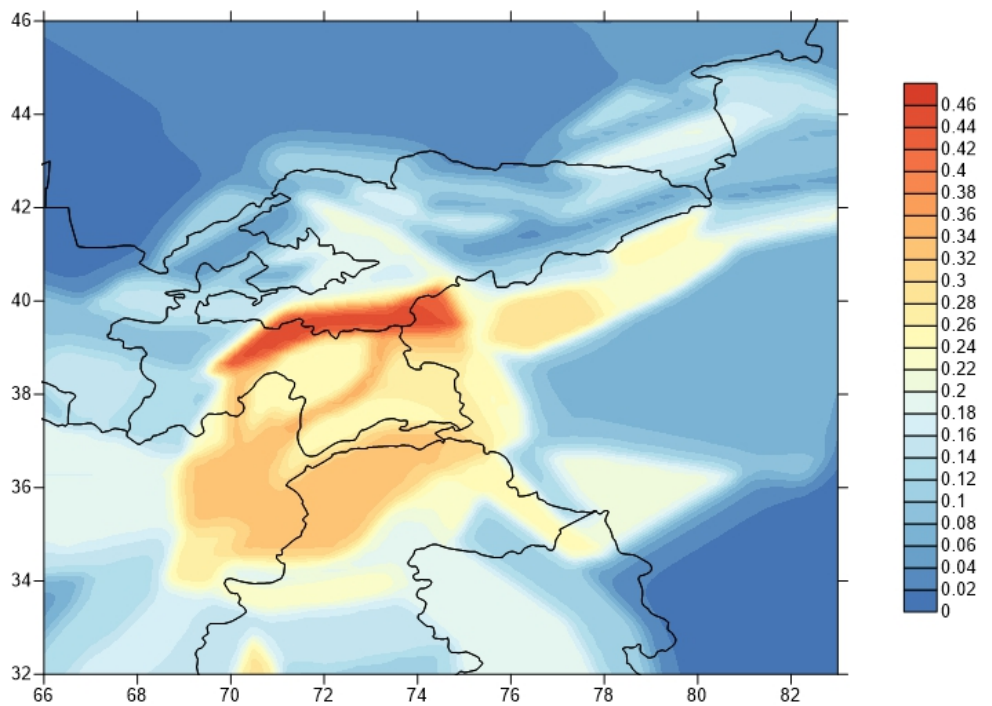

Fig. 10. Seismic hazard result calculated by EMCA-EMME model (PGA with $10 \%$ probability of exceedance in 50 years) 


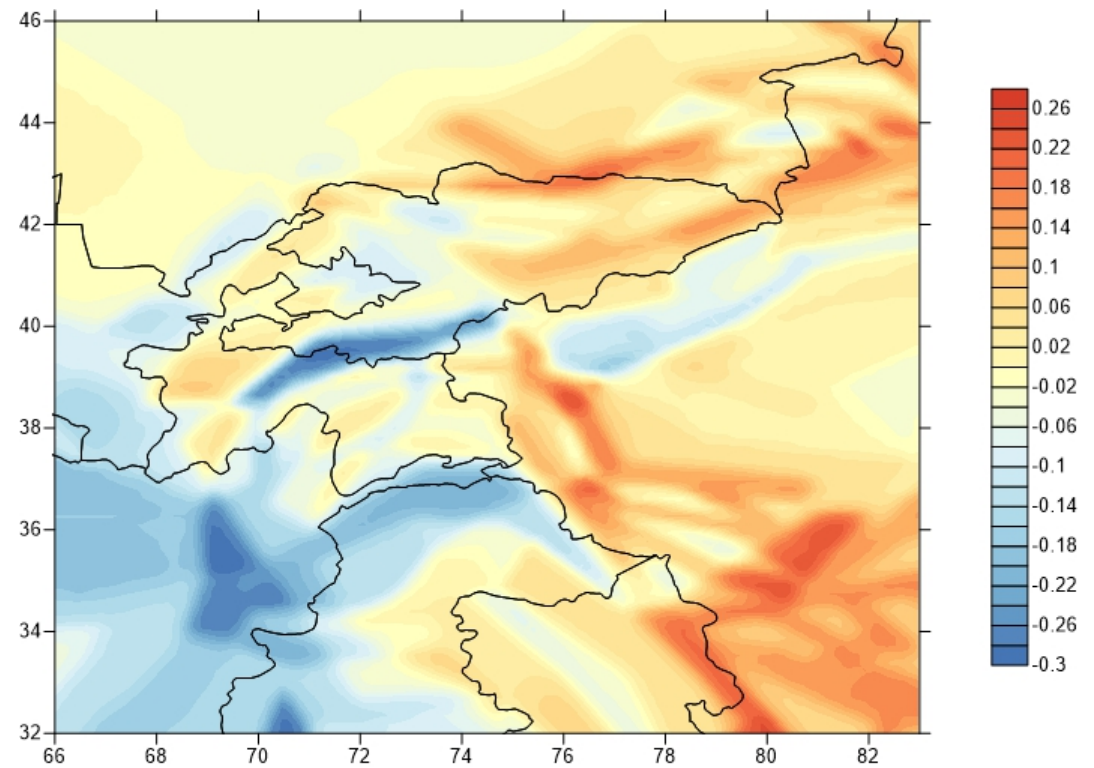

11. Result difference between China and EMCA-EMME (China minus EMCA-EMME)

the two models are quite different both in and outside China. But the difference is not very large across the border. This seems that a harmonized seismic hazard result is possible.

\subsection{Source model harmonization}

We can see sources by three institutions in South Tienshan Area as shown in Fig. 12. To do harmonization, we managed to delete entire pieces of overlapped sources as shown in Fig. 13. Then we sew the edges and gaps, as shown in Fig. 14.

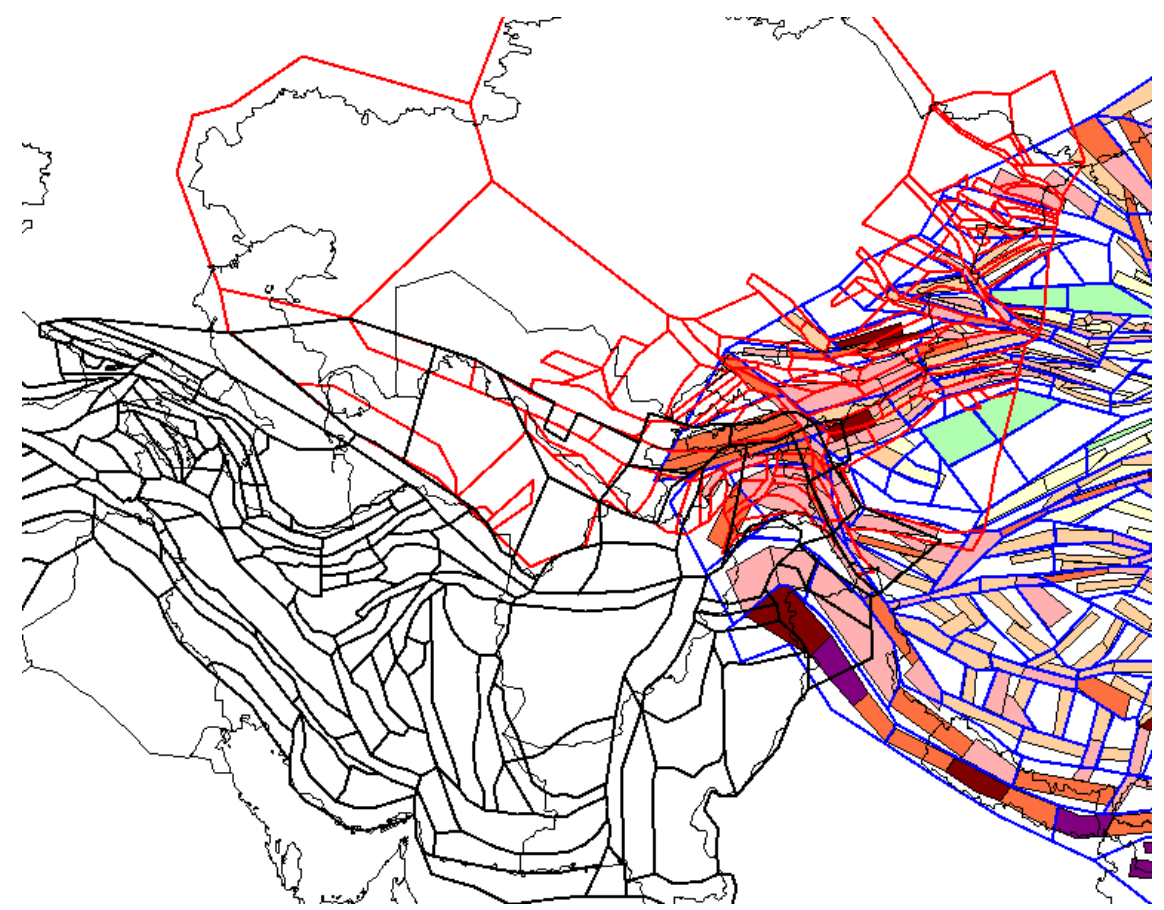

Fig. 12. Sources by three institutions in South Tienshan Area

\subsection{Changing seismicity parameters}

For the sources whose areas are changed, their seismicity parameters should also be changed. For one source, it has a-value and b-value according to Gutenberg-Richter relationship. We suppose its original a-value is a, and a' after changing. Then a' can be calculated by

$$
a^{\prime}=\lg \left(10^{a} \cdot \frac{S^{\prime}}{S}\right)
$$

Where S and S' are source's areas before and after harmonization. Then we get a harmonized 


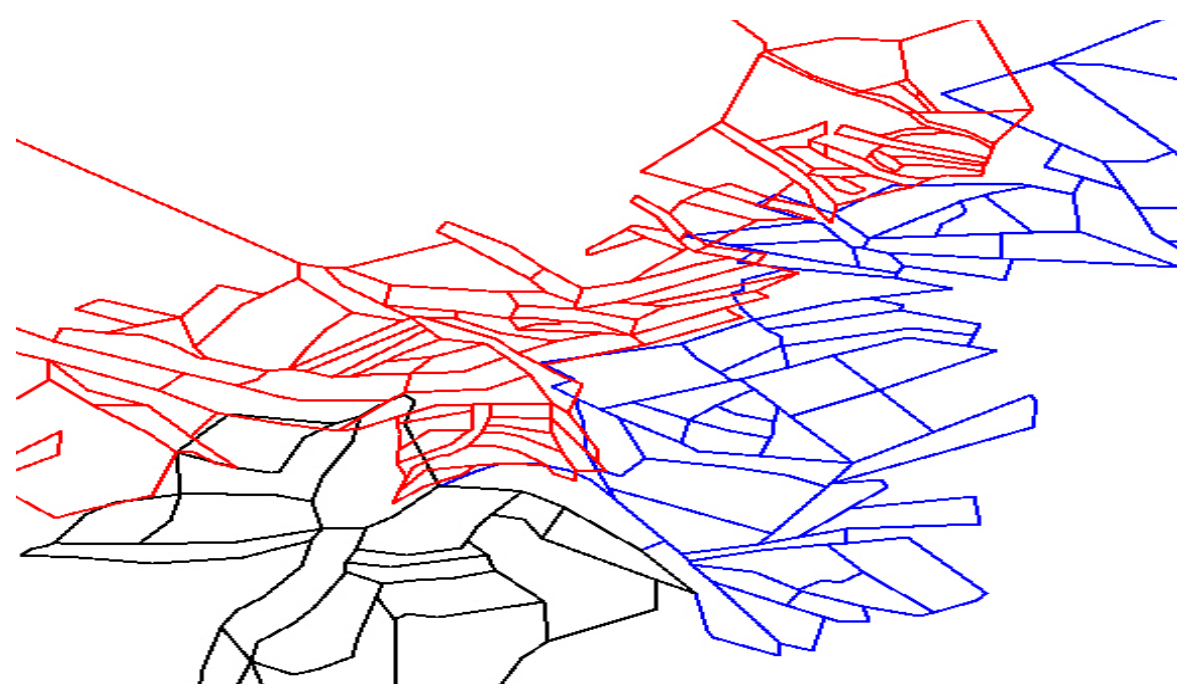

Fig. 13. Sources after deleting entire pieces of overlapped ones.

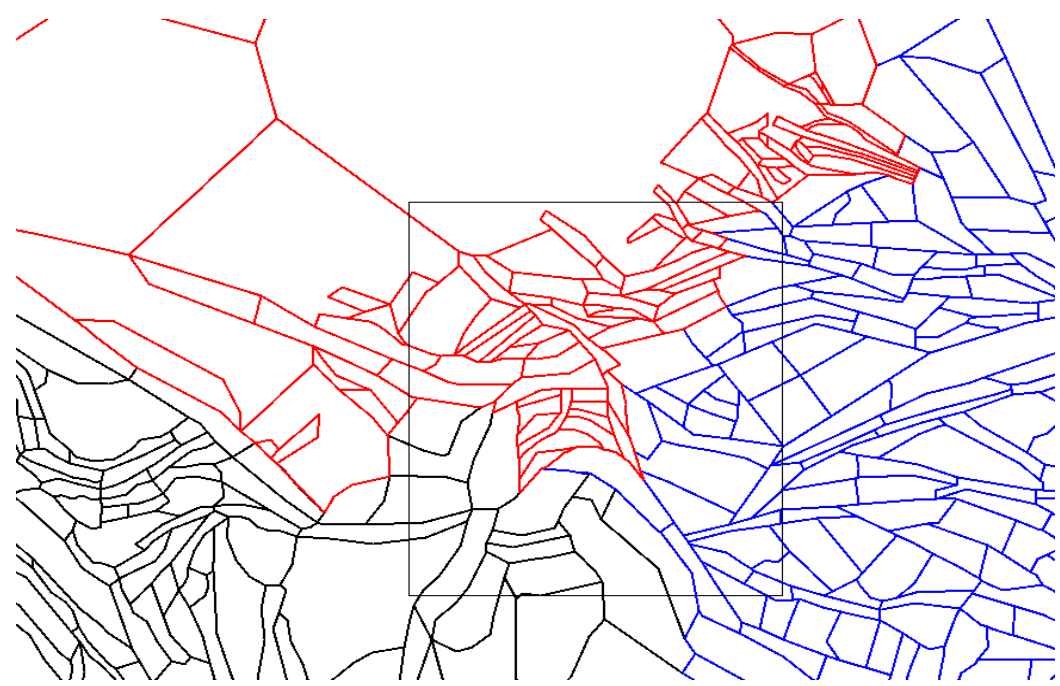

Fig. 14. Sources after sewing edges

source separation of South Tienshan as shown in Fig. 15

\subsection{Fault model harmonization}

In EMCA and China model, only area source model is used without faults. But EMME model contains active faults. In this part, we collected fault data in Tienshan Area. We built 122 fault sources in China and Central Asia, and together with the 53 fault sources in EMME, the fault source model of the South Tienshan Area is formed, as shown in Fig. 16.

The parameters of the faults used in PSHA are strike, dip, rake, depth, slip rate, aspect ratio, and b-value in G-R relationship (Gutenberg and Richter, 1944). For faults in China and EMCA, the $b$-value is determined the same as the $\mathrm{b}$-value of the seismic belt where the fault is.
And a-value is calculated by the slip rate of the fault using the relationship of the slip rate and the earthquake occurrence rate developed by Anderson and Luco (1983):

$$
M=\frac{1}{d} \ln \left[\frac{d-b}{d} \frac{\mu S T}{M_{0}}\right]
$$

Where $M$ is magnitude, $T$ is earthquake recurrence cycle, $d$ is the fault slip rate, $b$ is b-value, $\mu$ is the shear modulus, and $S$ is the fault plane area.

For the area sources with faults in it, the seismicity should be separated into both area and fault. In this study, we consider a maximum magnitude of 6.5 for such area sources, and the minimum magnitude of fault sources is 6.5 . In this way, the seismicity in the region will not be under or over calculated. 


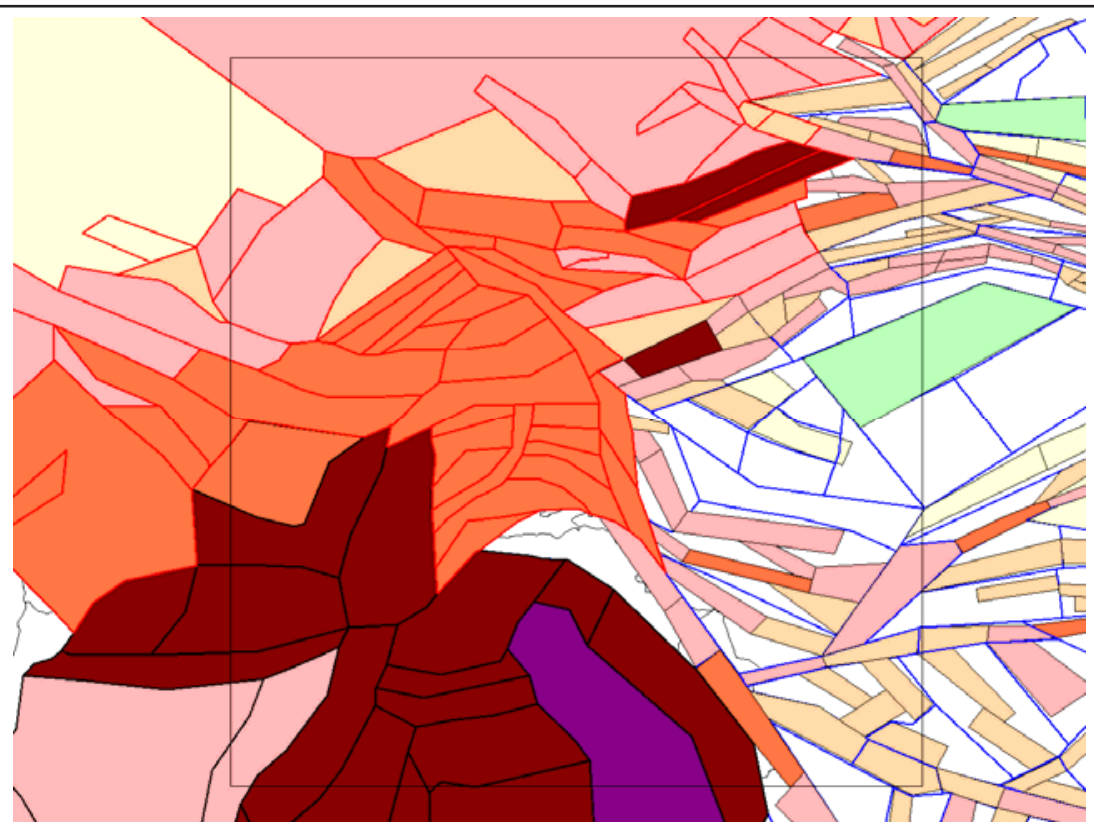

Fig. 15. Harmonized source separation of South Tienshan

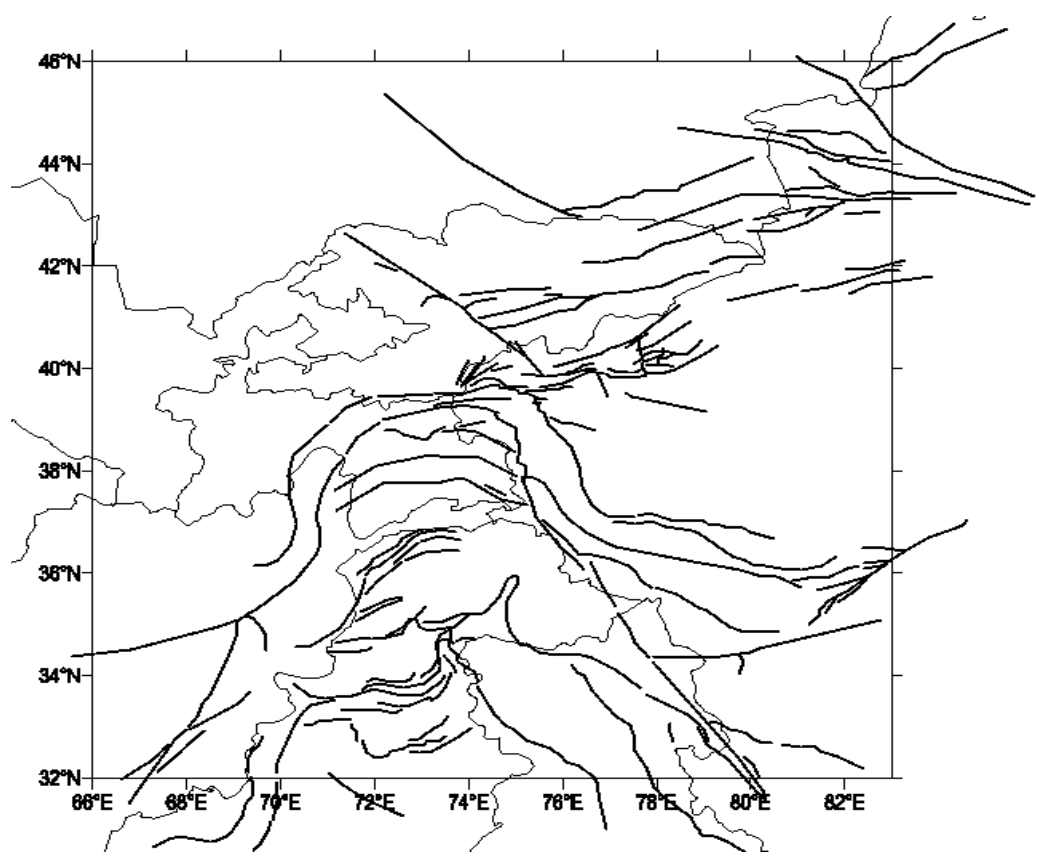

Fig. 16. Fault source model in South Tienshan Area

\subsection{Choosing Ground Motion Prediction}

\section{Equation (GMPE)}

The harmonized source model should use the same GMPE model. For area sources, we chose $\mathrm{Yu}$ et al. (2013)'s GMPE which is used in Seismic hazard map of China. The equation is as follows:

$$
\lg Y=A+B M+C \lg \left(R+D e^{E M}\right)
$$

where $\mathrm{Y}$ is ground motion parameters, $\mathrm{M}$ is magnitude, $\mathrm{R}$ is epicenter, $\mathrm{A}, \mathrm{B}, \mathrm{C}, \mathrm{D}$ and $\mathrm{E}$ are constants.

For fault sources, we used the same GMPEs as used in EMME model, which have a logic tree shown in Fig. 17.

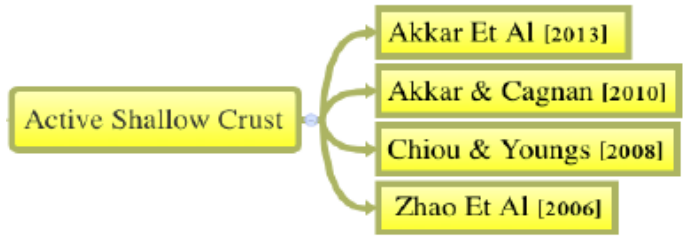

Fig. 17. Logic tree of the GMPEs for fault sources 


\subsection{Seismic hazard result}

The seismic hazard map of PGA with $10 \%$ probability of exceedance in 50 years of South Tienshan by harmonized model is shown in Fig. 18. From the hazard map, we can find western part of South Tienshan has the highest seismic hazard. In Central Xinjiang and the center of Central Asia, seismic hazard is low.

\section{Seismic Hazard Model Harmonization of North Tienshan}

Using the same method as South Tienshan, we also made a Seismic Hazard Model Harmonization for North Tienshan. The harmonized seismic hazard map of PGA with $10 \%$ probability of exceedance in 50 years of North Tienshan is shown in Fig. 19. It is shown that areas along North Tienshan Ridge have high seismic hazard. In Northern Xinjiang and Northern Kazakhstan, Seismic hazard is low.

\section{Conclusions}

From the study above, we can get several conclusions as follows:

(1) Western part of South Tienshan has the highest seismic hazard.

(2) In Central Xinjiang and the center of Central Asia, seismic hazard is low.

(3) Areas along North Tienshan Ridge have high seismic hazard.

(4) In Northern Xinjiang and Northern Kazakhstan, Seismic hazard is low.

There are also some topics that need discussion:

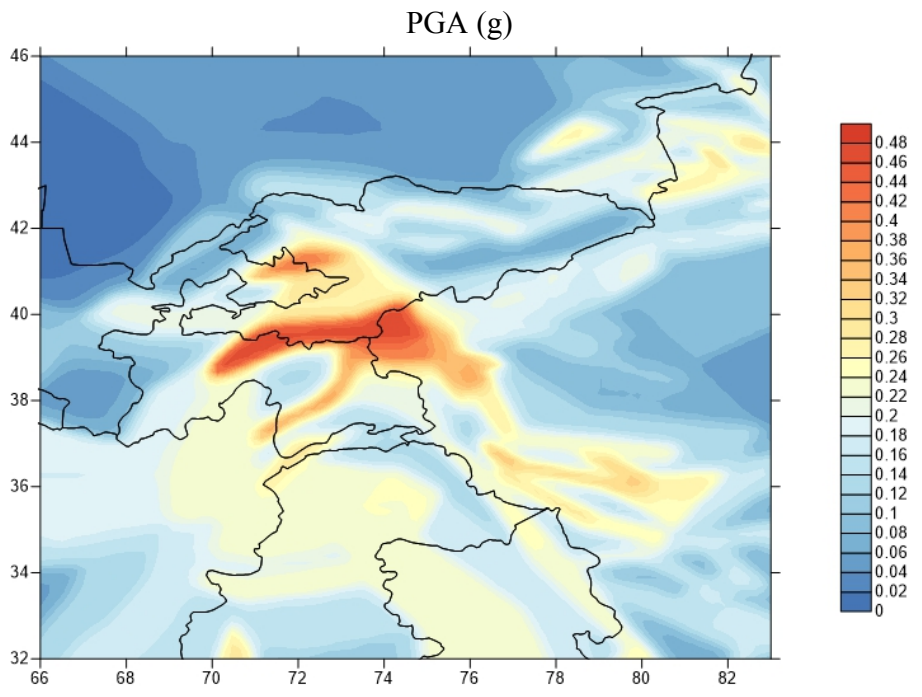

Fig. 18. Seismic hazard map of PGA with $10 \%$ probability of exceedance in 50 years of South Tienshan by harmonized model.

PGA (g)

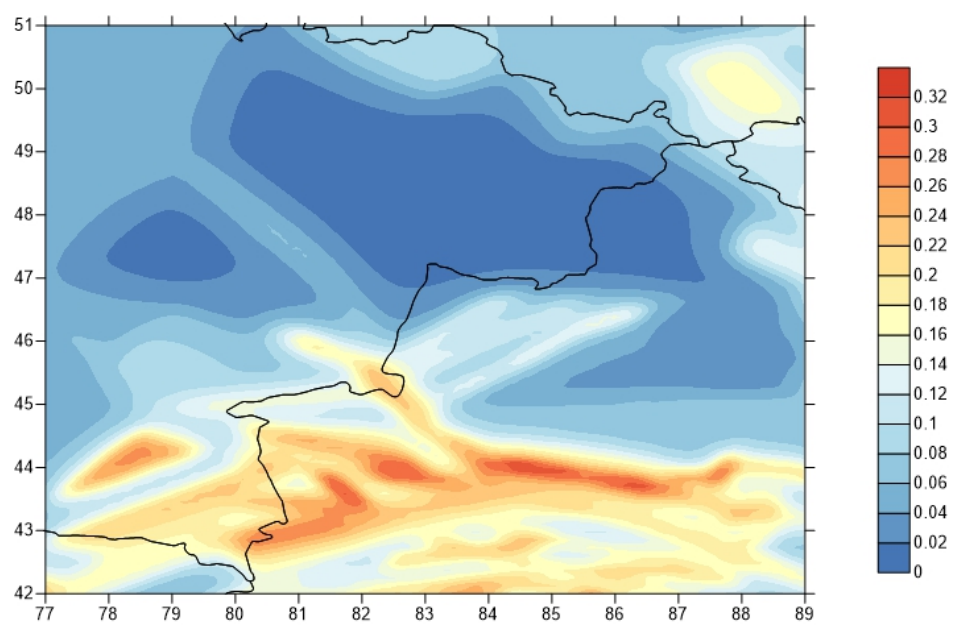

Fig. 19. Seismic hazard map of PGA with $10 \%$ probability of exceedance in 50 years of North Tienshan by harmonized model. 
(1) When dealing with seismicity parameter harmonization, we took a simple way that changes a source's parameter according to its area change with the assumption that the seismicity is the same on unit area. There is also a more precise way that using earthquake catalog to get the seismicity parameter.

(2) Along borders, different models lead to different hazard result for the same place. The reason of the difference needs more study in the future.

(3) We took the GMPE of Yu et al. (2013) as the harmonized GMPE. It needs to study if it is the most suitable one.

\section{Acknowledgments}

Thanks to Xinjiang Earthquake Agency who provided data of seismogenic structures in Xinjiang for this study. The PSHA calculation in this study is based on OpenQuake developed by GEM Foundation (Silva et al., 2012).This paper is sponsored by International partnership program of Chinese Academy of Sciences (131551KYSB20160002); Fundamental Scientific Research Fund (DQJB17T04). This paper is correspondence to: Changlong Li, Institute of Geophysics, China Earthquake Administration, No. 5 Minzu Daxue Nanlu Road, Beijing 100081, China. Tel: +86 10 68729162; Fax: +86 10 68729162; E-mail: changlongli@163.com.

\section{References}

Akkar S, Cagnan Z. 2010. A local ground-motion predictive model for Turkey, and its comparison with other regional and global ground-motion models. Bulletin of the Seismological Society of America, 100(6), 2978-2995.

Akkar S, Sandikkaya M A, Bommer J J. 2014. Empirical ground-motion models for point-and extended-source crustal earthquake scenarios in Europe and the Middle East. Bulletin of earthquake engineering, 12(1), 359-387.

Bindi D, Abdrakhmatov K, Parolai S, et al. 2012. Seismic hazard assessment in Central Asia: Outcomes from a site approach. Soil Dynamics and Earthquake Engineering, 37, 84-91.

Bindi D, Pacor F, Luzi L, et al. 2011. Ground motion prediction equations derived from the Italian strong motion database. Bulletin of Earthquake Engineering, 9(6), 1899-1920.

Chiou B J, Youngs R R. 2008. An NGA model for the average horizontal component of peak ground motion and response spectra. Earthquake Spectra, 24(1), 173-215.
Danciu L, Giardini D, Sesetyan K. 2015. Seismic Hazard Assessment in the Middle East Region. Earthquake Model of the Middle East Region Project.

Gao Z W, Chen G X, Zhou B G, et al. 2014. The principles and techniques of identifying seismotectonic province in new national seismic zoning map of China - an example of East China with middle seismic activity. Technology for Earthquake Disaster Prevention (in Chinese), 9(1), 1-11.

General Administration of Quality Supervision, Inspection and Quarantine of the People's Republic of China, China National Standardization Administration Committee. 2015. Seismic hazard map of China. GB 18306-2015.

Giardini D, Wössner J, Danciu L. 2014. Mapping Europe's seismic hazard. Eos, Transactions American Geophysical Union, 95(29), 261-262.Gutenberg B, Richter C F. 1944. Frequency of earthquakes in California. Bulletin of the Seismological Society of America, 34(4), 185-188.

Pagani M, Garcia J, Monelli D, et al. 2015. A summary of hazard datasets and guidelines supported by the Global Earthquake Model during the first implementation phase. Annals of Geophysics, 58(1).

Silva V, Crowley H, Pagani M, et al. 2012. Development and application of OpenQuake, an open source software for seismic risk assessment. Proceedings of the 15th World Conference on Earthquake Engineering, Lisbon, Paper No. 4923.

Ullah S, Bindi D, Pilz M, et al. 2015. Probabilistic seismic hazard assessment for Central Asia. Ann. Geophys. 58(1), 0103S.

Yu Y X, Li S Y, Xiao L. 2013. Development of Ground Motion Attenuation Relations for the New Seismic Hazard Map of China. Technology for Earthquake Disaster Prevention (in Chinese), 8(1), 24-33.

Zhang P Z, Deng Q D, Zhang G M, et al. 2003. Active tectonic blocks and strong earthquakes in continental China. Science in China (Series D), 46 (Supplement), 13-24.

Zhao J X, Zhang J, Asano A, et al. 2006. Attenuation relations of strong ground motion in Japan using site classification based on predominant period. Bulletin of the Seismological Society of America, 96(3), 898-913.

Zhou B G, Chen G X, Gao Z W, et al. 2013. The technical highlights in identifying the potential seismic sources for the update of national seismic zoning map of China. Technology for Earthquake Disaster Prevention (in Chinese), 8(2), 113-124. 